\title{
New Techniques for \\ Optimization of Donor \\ Lungs/Hearts
}

Sue A. Braithwaite, $\mathrm{MBChB}^{\mathrm{a}, *}$, Niels P. van der Kaaij, $\mathrm{PhD}, \mathrm{MD}^{\mathrm{b}}$

\section{KEYWORDS}

- Optimization of heart and lung allografts $\bullet$ Lung transplantation

- Heart transplantation $\bullet$ EVLP • EVHP • Primary graft dysfunction • Novel therapies

\section{KEY POINTS}

- Primary graft dysfunction of both heart and lung allografts can have a disastrous effect on outcomes after transplantation.

- The injuries occurring in donor heart and lung allograft span the entire transplant process and are multiple and cumulative in nature. Donor, recipient, and preservation issues play a role.

- Marginal lung or heart allografts are more vulnerable to injury incurred during preservation and transplantation.

- Techniques to optimize donor heart and lung allograft preservation and function have a role in improving outcomes of transplantation and expanding the donor pool.

- There is great potential for future research into novel therapies to optimize donor heart and lung allografts. Ex vivo perfusion can play a vital role.

Video content accompanies this article at www.anesthesiology.theclinics.com.

\section{INTRODUCTION: CLINICAL RELEVANCE OF HEART AND LUNG TRANSPLANTATION}

Lung transplantation is at present the only life-prolonging therapy for end-stage lung failure or end-stage vascular lung disease. A wide range of pathologic lung conditions can progress with varying speed to a situation whereby lung function can no longer support life. Affected patients benefit from lung transplantation, the use of lung allografts from deceased patients to replaced diseased lung(s) in the recipient.

Owing to advances in surgical technique, perioperative support, and immunosuppressive therapies, lung transplantation is now an accepted and widely used

Disclosure Statement: Both authors have no disclosures.

a Department of Anesthesiology, University Medical Center Utrecht, Mail Stop Q04.2.317, Postbus 85500, Utrecht 3508 GA, The Netherlands; b Department of Cardiothoracic Surgery, University Medical Center Utrecht, Room E03.511, Heidelberglaan 100, Utrecht 3584 CX, The Netherlands

* Corresponding author.

E-mail address: s.a.braithwaite@umcutrecht.nl 
procedure. Annually, approximately 4100 lung transplants are performed worldwide ${ }^{1}$ (Fig. 1, survival demonstrated in Fig. 2), a number that has stagnated in recent years because of a limit in the number of available donor lungs.

In contrast to end-stage respiratory failure, most patients with terminal heart failure have an alternative to heart transplant for the medium or long term in the form of mechanical circulatory support (MCS). One of the major indications for long-term MCS is to "bridge" the wait to transplantation for otherwise terminal heart-failure patients, offering the opportunity for clinical improvement and preventing worsening secondary end-organ damage. However, for younger patients, or patients who poorly tolerate MCS (eg, biventricular failure, or issues with MCS such as drive-line infections or gastrointestinal bleeding), heart transplant remains the preferred therapy. Annually, approximately 5000 heart transplants are performed worldwide (Fig. 3, with survival according to preoperative MCS support shown in Fig. 4).

The common themes dominating heart and lung transplantation are the shortage of standard donor organs (Box 1, Table 1) and an increasingly complex recipient population, both factors that adversely affect waiting-list and transplant outcomes. Fortunately, new techniques are being developed to optimize donor heart and lung allograft function to both improve outcome and quality of life after transplant and to expand the donor pool by using "nonstandard" or marginal allografts. This review explores the clinical relevance of donor heart and lung allograft injury, mechanisms of injury, and ways in which to optimize donor heart and lung allograft function.

\section{CLINICAL RELEVANCE OF PRIMARY GRAFT DYSFUNCTION/FAILURE IN HEART TRANSPLANTATION}

In 2011 a definition of primary graft failure (PGF) after heart transplantation (HTx) was proposed based on a retrospective analysis of 621 consecutive heart transplants, ${ }^{2}$ resulting in 4 criteria:

1. Significant impairment of systolic graft function affecting right, left or both ventricles during HTx or shortly thereafter

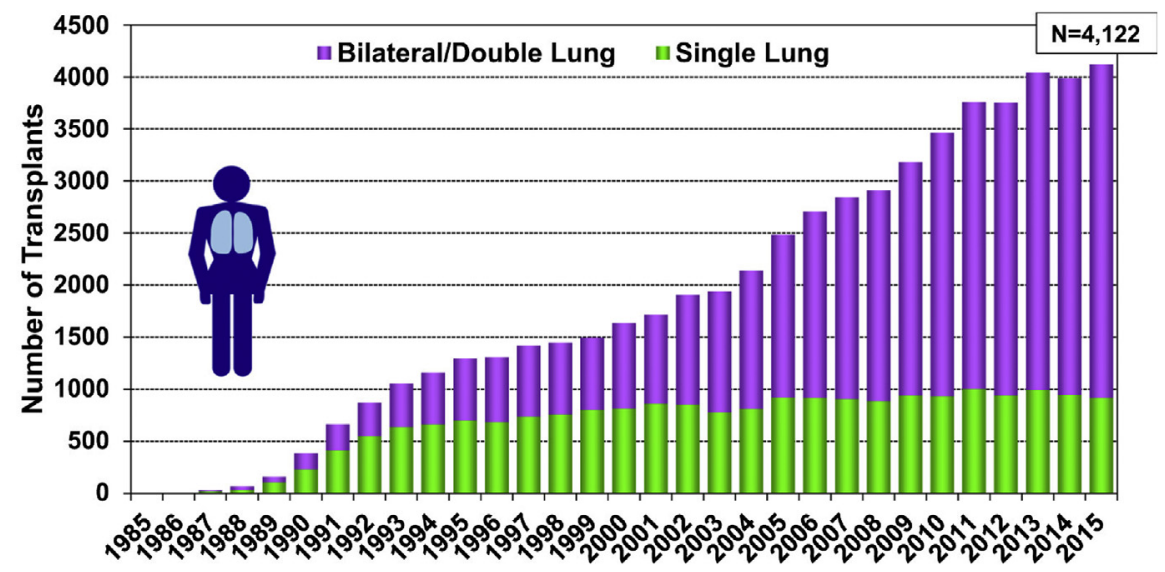

Fig. 1. Number of adult lung transplants reported to the International Society for Heart and Lung Transplantation Registry by year and procedure type. (From Chambers DC, Yusen RD, Cherikh WS, et al. The registry of the International Society for Heart and Lung Transplantation: Thirty-fourth Adult Lung And Heart-Lung Transplantation Report-2017; Focus Theme: Allograft ischemic time. J Heart Lung Transplant 2017;36(10):1048; with permission.) 


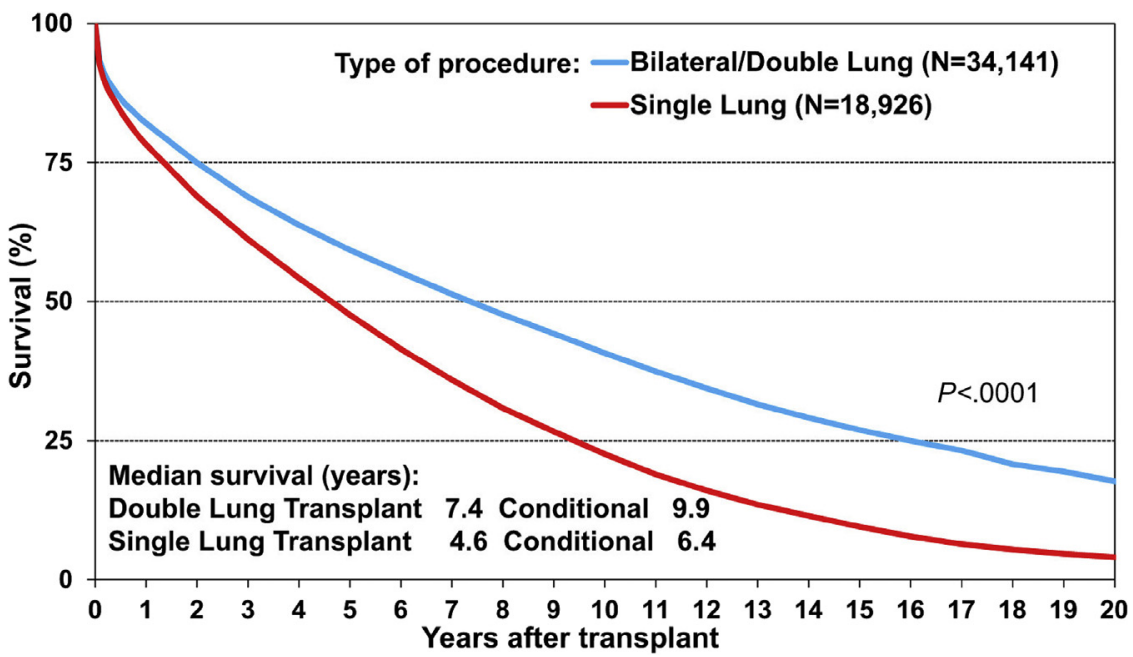

Fig. 2. Kaplan-Meier survival for adult lung transplant recipients by procedure type (transplants: 1990 to June 2015). Conditional median survival is the estimated time to $50 \%$ survival for the subset of recipients alive at 1 year after transplantation $(P<.0001$ by log-rank test statistic). (From Chambers DC, Yusen RD, Cherikh WS, et al. The registry of the International Society for Heart and Lung Transplantation: Thirty-fourth Adult Lung And Heart-Lung Transplantation Report-2017; Focus Theme: Allograft ischemic time. J Heart Lung Transplant 2017;36(10):1048; with permission.)

2. Severe hemodynamic compromise lasting greater than 1 hour manifested as hypotension (systolic blood pressure $<90 \mathrm{~mm} \mathrm{Hg}$ ) and/or low cardiac output (cardiac index $<2.2 \mathrm{~L} / \mathrm{min} / \mathrm{m}^{2}$ ) requiring $\geq 2$ intravenous inotropic/pressor drugs, or MCS despite appropriate filling pressures

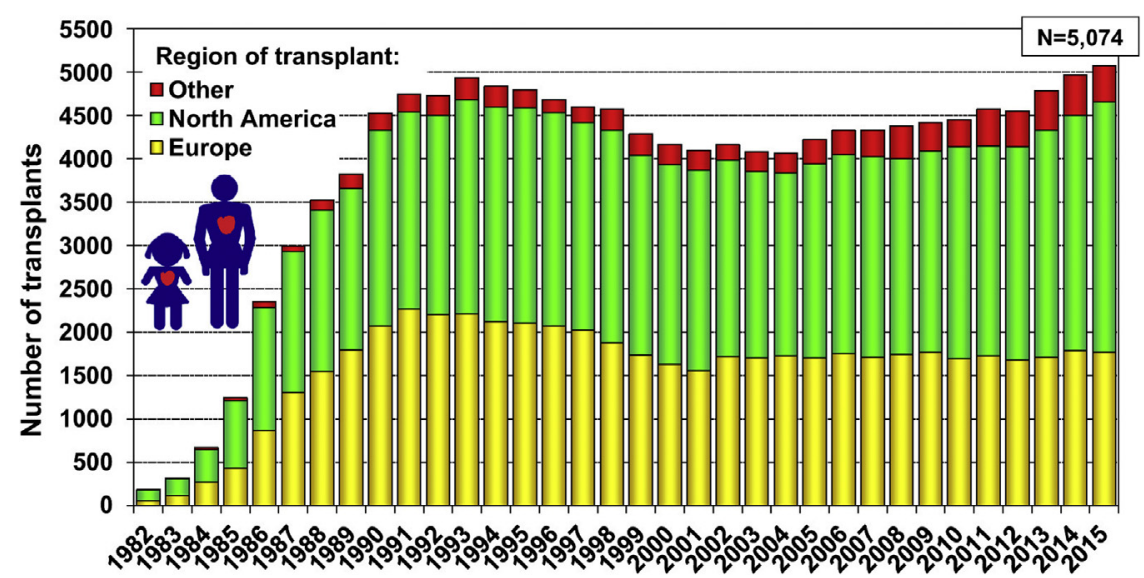

Fig. 3. Number of adult and pediatric heart transplants by year (transplants 1982-2015) and geographic region. (From Lund LH, Khush KK, Cherikh WS, et al. The registry of the International Society for Heart and Lung Transplantation: Thirty-fourth Adult Heart Transplantation Report-2017; Focus Theme: Allograft ischemic time. J Heart Lung Transplant 2017;36(10):1039; with permission.) 


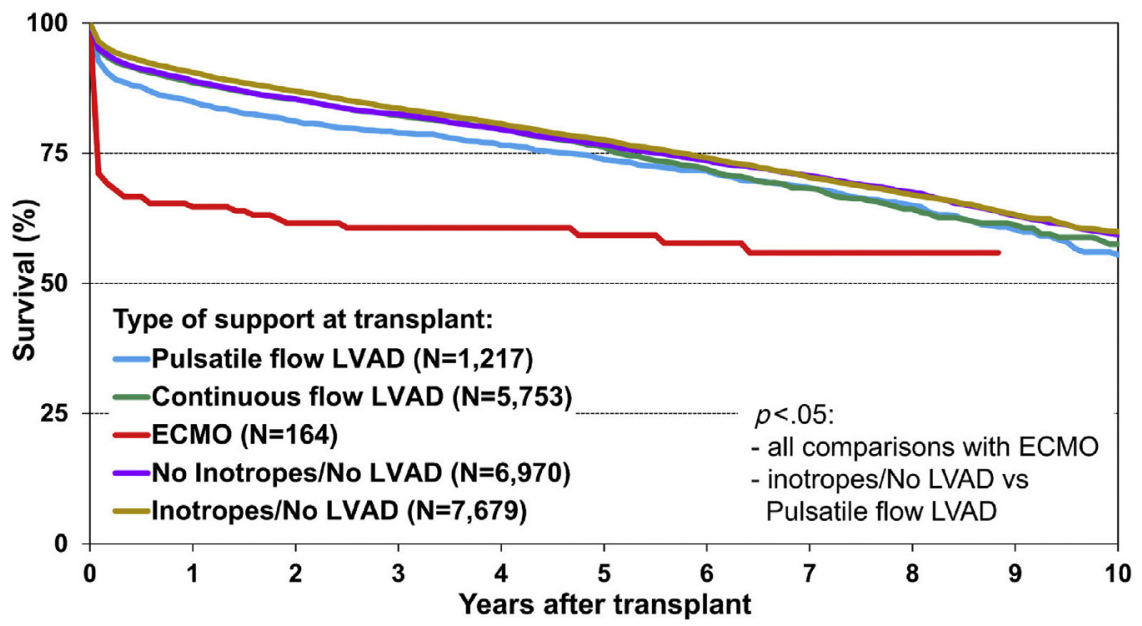

Fig. 4. Kaplan-Meier intermediate-term survival by pretransplant MCS use (adult heart transplants: January 2005 to June 2015). ECMO, extracorporeal membrane oxygenation; LVAD, left ventricular assist device. (From Lund LH, Khush KK, Cherikh WS, et al. The registry of the International Society for Heart and Lung Transplantation: Thirty-fourth Adult Heart Transplantation Report-2017; Focus Theme: Allograft ischemic time. J Heart Lung Transplant 2017;36(10):1039; with permission.)

3. Occurrence within 24 hours after HTx

4. Absence of any other obvious cause of graft dysfunction (hyperacute rejection, severe pulmonary hypertension, massive hemorrhage, and technical problems)

Building on this, the International Society for Heart and Lung Transplant (ISHLT) issued a report in 2014 on primary graft dysfunction after HTx. ${ }^{3}$ Their classification and definition of severity scale for primary graft dysfunction is presented in Box 2 and Table 2.

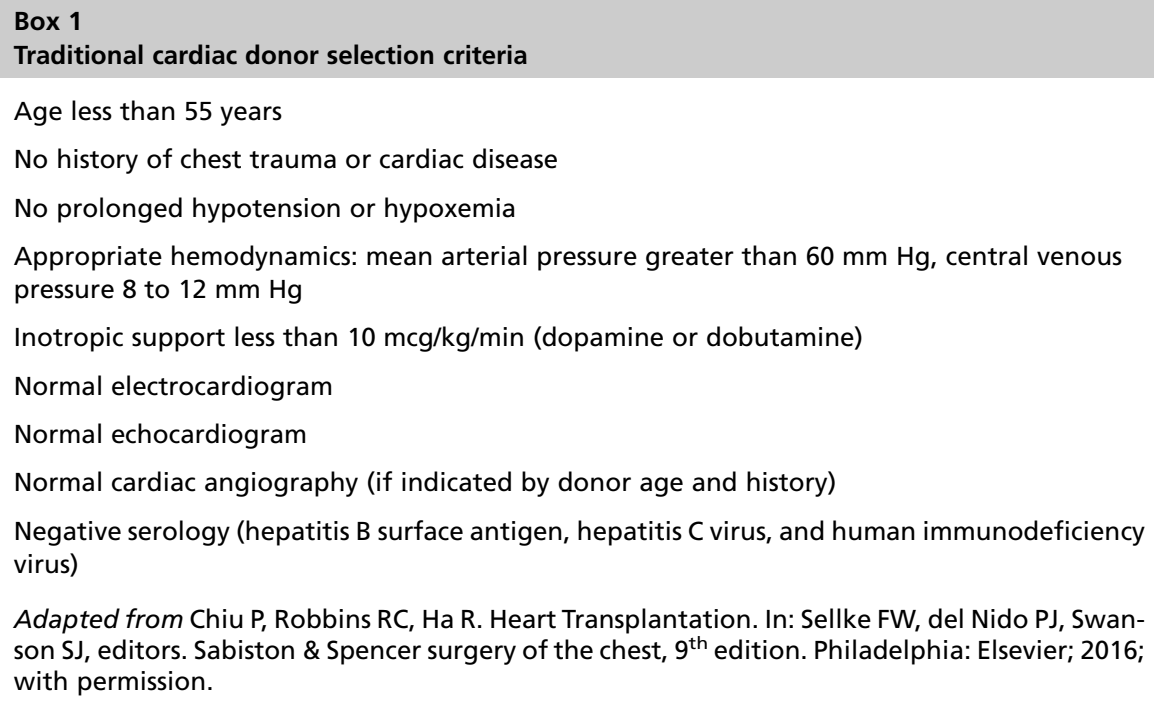

Adapted from Chiu P, Robbins RC, Ha R. Heart Transplantation. In: Sellke FW, del Nido PJ, Swanson SJ, editors. Sabiston \& Spencer surgery of the chest, $9^{\text {th }}$ edition. Philadelphia: Elsevier; 2016; with permission. 


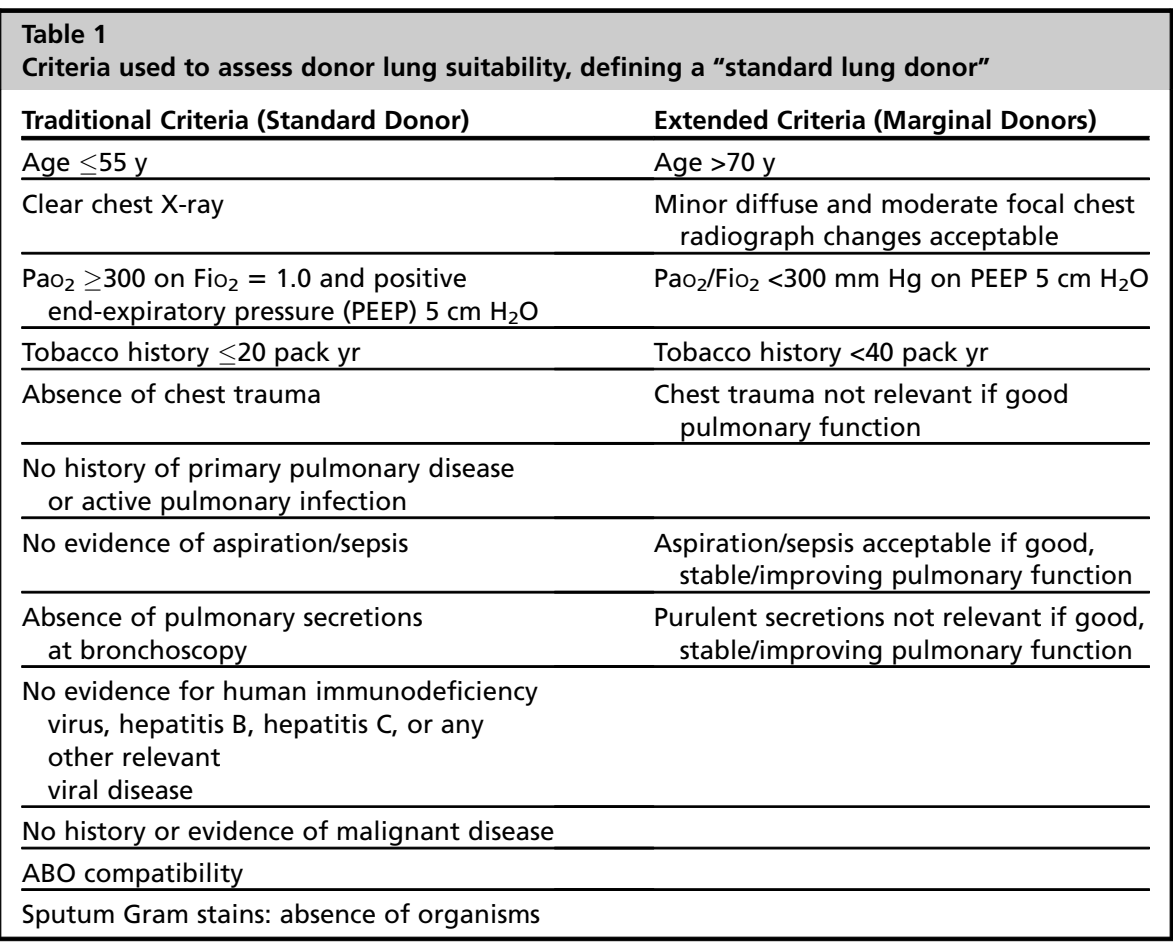

From Van Raemdonck D, Coosemans W, Klepetko W, et al. Alternatives to lung donor shortage. Eur Respir Mon 2004;29:89-112. Reproduced with permission of the ๑ ERS 2019.

PGF is the leading cause of early mortality in HTx, accounting for more than $35 \%$ of deaths within 30 days postoperatively. ${ }^{4}$ Using the PGF criteria from 2011 , a study by the same group looked at the incidence of PGF in a multicenter cohort of 857 heart transplants. ${ }^{5}$ The incidence of PGF was $22 \%$ with a corresponding early mortality of $53 \%$, compared with $7 \%$ in patients without PGF $(P=.001)$.

\section{CLINICAL RELEVANCE OF PRIMARY GRAFT DYSFUNCTION IN LUNG TRANSPLANTATION}

PGD after lung transplantation describes a clinical syndrome of varying degrees of hypoxemia together with presence of diffuse alveolar infiltrates on chest radiography. In

\section{Box 2}

Classification of graft dysfunction after heart transplantation

1. Primary graft dysfunction (PGD):

a. PGD in left ventricle (PGD-LV): includes left and biventricular dysfunction

b. PGD in right ventricle (PGD-RV): Includes right ventricular function alone

2. Secondary graft dysfunction: occurs when there is a discernible cause for graft dysfunction (eg, hyperacute rejection, pulmonary hypertension, known surgical complication)

From Kobshigawa J, Zuckermann A, Macdonald P, et al. Report from a consensus conference on primary graft dysfunction after cardiac transplantation. J Heart Lung Transplant 2014;33(4):337; with permission. 


\begin{tabular}{|c|c|c|}
\hline \multirow[t]{4}{*}{$\begin{array}{l}\text { 1. PGD in left } \\
\text { ventricle (PGD-LV) }\end{array}$} & $\begin{array}{l}\text { Mild PGD-LV: one of the } \\
\text { following criteria must } \\
\text { be met: }\end{array}$ & $\begin{array}{l}\text { LVEF }<40 \% \text { by echocardiography, } \\
\text { or hemodynamics with } \\
\mathrm{RAP}>15 \mathrm{~mm} \mathrm{Hg}, \mathrm{PCWP}>20 \mathrm{~mm} \\
\mathrm{Hg}, \mathrm{Cl}<2.0 \mathrm{~L} / \mathrm{min} / \mathrm{m}^{2} \text { (lasting } \\
\text { more than } 1 \mathrm{~h} \text { ) requiring } \\
\text { low-dose inotropes }\end{array}$ \\
\hline & $\begin{array}{l}\text { Moderate } P G D-L V \text { : must } \\
\text { meet one criteria from I } \\
\text { and another criteria from II }\end{array}$ & $\begin{array}{l}\text { I. One criterion from the } \\
\text { following: } \\
\text { - Left ventricular ejection } \\
\text { fraction }<40 \% \text {, or } \\
\text { - Hemodynamic compromise } \\
\text { with RAP }>15 \mathrm{~mm} \mathrm{Hg} \text {, } \\
\text { PCWP }>20 \mathrm{~mm} \mathrm{Hg} \text {, } \\
\mathrm{Cl}<2.0 \mathrm{~L} / \mathrm{min} / \mathrm{m}^{2} \text {, } \\
\text { hypotension with } \\
\text { MAP }<70 \mathrm{~mm} \mathrm{Hg} \text { (lasting } \\
\text { more than } 1 \mathrm{~h} \text { ) }\end{array}$ \\
\hline & & $\begin{array}{l}\text { II. One criterion from the } \\
\text { following: } \\
\text { i. High-dose inotropes } \\
\text { ii. Newly placed IAPB } \\
\text { (regardless of inotropes) }\end{array}$ \\
\hline & Severe $P G D-L V$ & $\begin{array}{l}\text { Dependence on left or } \\
\text { biventricular mechanical } \\
\text { support including ECMO, LVAD, } \\
\text { BiVAD, or percutaneous LVAD. } \\
\text { Excludes requirement for IABP }\end{array}$ \\
\hline $\begin{array}{l}\text { 2. } P G D \text { in right } \\
\text { ventricle (PGD-RV) }\end{array}$ & $\begin{array}{l}\text { Diagnosis requires either both } \\
\text { i and ii, or iii alone: }\end{array}$ & $\begin{array}{l}\text { i. Hemodynamics with } \\
\text { RAP }>15 \mathrm{~mm} \mathrm{Hg} \text {, } \\
\text { PCWP }<15 \mathrm{~mm} \mathrm{Hg} \text {, } \\
\mathrm{Cl}<2.0 \mathrm{~L} / \mathrm{min} / \mathrm{m}^{2} \\
\text { ii. TPG }<15 \mathrm{~mm} \mathrm{Hg} \text { and/or } \\
\text { pulmonary artery systolic } \\
\text { pressure }<50 \mathrm{~mm} \mathrm{Hg} \text {, or } \\
\text { iii. Need for RVAD }\end{array}$ \\
\hline
\end{tabular}

Abbreviations: BiVAD, biventricular assist device; $\mathrm{Cl}$, cardiac index; $\mathrm{ECMO}$, extracorporeal membrane oxygenation; IABP, intra-aortic balloon pump; LVAD, left ventricular assist device; LVEF, left ventricular ejection fraction; PCWP, pulmonary capillary wedge pressure; RAP, right atrial pressure; RVAD, right ventricular assist device; TPG, transpulmonary pressure gradient.

Adapted from Kobshigawa J, Zuckermann A, Macdonald P, et al. Report from a consensus conference on primary graft dysfunction after cardiac transplantation. J Heart Lung Transplant 2014;33(4):337; with permission.

2005 the first ISHLT Working Group on PGD proposed a standardized definition and grading system ${ }^{6}$ (Table 3 ), and a validation of these definitions was performed in 2016. ${ }^{7}$ They described that PGD grade 3 was associated with higher mortality in the acute phase after lung transplantation (PGD grade 372 hours post transplant was associated with 30-day mortality relative risk of 6.95 compared with no PGD), and that all grades of PGD were associated with greater risk of bronchiolitis obliterans syndrome development in survivors. The literature supports incidences of PGD of $\sim 30 \%$ early after transplant and a $15 \%$ to $20 \%$ incidence of PGD grade 3 at 48 to 72 hours. The time course of PGD progression and resolution has an effect on patient survival outcomes, with patients experiencing severe, persistent PGD having the greatest mortality risk. ${ }^{8}$ 


\begin{tabular}{|lll|}
\hline \multicolumn{2}{l}{ Table 3} \\
Grades of primary graft dysfunction after lung transplantation \\
Grade & $\mathrm{PaO}_{2} / \mathrm{FiO}_{\mathbf{2}}$ Ratio & Radiographic Infiltrates Consistent with Pulmonary Edema \\
\hline 0 & $>300$ & Absent \\
\hline 1 & $>300$ & Present \\
\hline 2 & $200-300$ & Present \\
\hline 3 & $<200$ & Present \\
\hline
\end{tabular}

Adapted from Christie JD, Carby M, Bag R, et al. Report of the ISHLT working group on primary lung graft dysfunction part II: Definition. A consensus statement of the International Society for Heart and Lung Transplantation. J Heart Lung Transplant 2005;24(10):1458; with permission.

It is unequivocal that PGD in heart and lung allografts is an important factor in causing early mortality and morbidity and is also strongly associated with late-onset morbidity. ${ }^{9}$ The goal of optimizing heart and lung donor allografts must then be to attenuate or treat the underlying causes of PGD. To achieve this, the mechanisms and timing of injury to heart and lung allografts must be identified.

\section{RISK FACTORS FOR PRIMARY GRAFT DYSFUNCTION IN HEART AND LUNG ALLOGRAFTS}

Although specific causes and associations have been linked to an increased risk of developing PGD after heart and lung transplant, similarities between the two exist in that a "multihit" model spanning the entire transplantation process may be envisaged. This multihit model may be seen as a heterogeneous, dynamic accumulation of different injuries incurred at different stages in the transplant process, involving:

- Donor comorbidity/social history

- Management of the donor patient

- The donation procedure

- Procurement and preservation of the donor organ

- Organ reperfusion in the recipient

- Recipient comorbidity

- Factors in the transplant procedure and postoperative phase

A large number of studies have highlighted the association of recipient-related risk factors with the development of PGD in lung transplantation. In a systemic review, the incidence of PGD was shown to be highest in patients with a pretransplant diagnosis of sarcoidosis (50\%) or idiopathic pulmonary arterial hypertension $(30.3 \%) .^{10}$ One study showed an increased risk of PGD of $30 \%$ for every $10 \mathrm{~mm} \mathrm{Hg}$ increase in mean pretransplant pulmonary artery pressure. ${ }^{11}$ Another study found that a combination of increased body mass index, moderate to severe pulmonary arterial hypertension, and a pretransplant diagnosis other than chronic obstructive pulmonary disease or cystic fibrosis could identify recipients at higher risk of PGD at 48 to 72 hours. ${ }^{12}$

With respect to donor-related post-lung transplant PGD risk factors, meta-analysis showed that donor cigarette smoking increased PGD risk mainly for "high-risk" recipients ${ }^{12}$ while other probable risk factors include an undersized donor relative to the recipient. ${ }^{8}$ Another systematic review showed that there was no association of the type of donation procedure, either donation after cardiac death (DCD) or donation after brain death (DBD) with PGD risk. ${ }^{13}$

Operative risk factors for PGD are previous pleurodesis in the recipient, ${ }^{14}$ use of cardiopulmonary bypass during the procedure, large-volume intraoperative blood 
product transfusion, and a higher inspired oxygen fraction $\left(\mathrm{FiO}_{2}\right)$ at the time of donor lung reperfusion. ${ }^{11}$

There are numerous recurring donor-, intraoperative-, and recipient-related factors seen in the literature that may be linked to the development of PGD in heart allografts. Major recipient-related factors are linked to increasing age, presence of pulmonary arterial hypertension, and worse pretransplant clinical condition (including dependence on intravenous inotropic support, MCS, and mechanical ventilation). ${ }^{3}$ The only validated scoring system for the prediction of PGD after HTx is the RADIAL score, which identified 6 factors with similar weight (risk ratio $\sim 2$ ), with 4 recipient-related factors (right atrial pressure $>10 \mathrm{~mm} \mathrm{Hg}$, Age $>60$ years, diabetes, inotropic support dependence), 1 related to the donor (age $>30$ years), and 1 to the procedure (allograft ischemia time $>240$ minutes). ${ }^{2}$ The presence of each of these factors adds 1 point to the total score. The score was validated in a large multicenter cohort showing 3 groups with low (0-1 points), medium ( 2 points), and high ( $\geq 3$ points) risk for PGD with an actual incidence in each group of $12 \%, 19 \%$, and $28 \%,{ }^{6}$ respectively.

\section{CAUSES OF INJURY IN THE DONOR AND DURING THE DONATION PROCEDURE Donation after Brain Death}

In a donation procedure following DBD, organs are perfused and ventilated with oxygenated blood up until the moment of procurement. Despite this, DBD donor organs may suffer significant injury from numerous insults, including iatrogenic insults (eg, excessive fluid resuscitation or suboptimal ventilation) and injury incurred secondary to processes inherent in brain death. Brain death is associated with a series of events including intense release of myocardial norepinephrine, resulting in massive mitochondrial calcium overload. ${ }^{15,16}$ This in turn may activate myocardial apoptosis or necrosis. Furthermore, a catecholamine storm also causes the activation of multiple proinflammatory mediators, ${ }^{17}$ leading to numerous sequelae, including injury to lung epithelium and disruption of the capillary-alveolar membrane causing ("neurogenic") lung edema and acute lung injury.

\section{Donation after Determination of Cardiac Death}

Uniform agreement on DCD donor candidacy includes ventilator-dependent individuals with nonrecoverable or irreversible neurologic injury not meeting brain death criteria. Such DCD donors, awaiting cardiac death in a controlled (typically intensive care unit [ICU]) setting, are denoted as "Maastricht category III" donors (with categories I, II, IV, and V being in "uncontrolled" settings ${ }^{18}$ ). After the withdrawal of lifesustaining therapy (WLST) in these donors, functional warm ischemia time (WIT) starts when the hemodynamic status reaches critical levels for satisfactory organ perfusion, denoted by a systolic pressure of $\leq 50 \mathrm{~mm} \mathrm{Hg}$. After the cessation of circulation (cardiopulmonary arrest), a locally determined "no-touch" time interval, typically 5 minutes, will ensue after which verification of death is performed, and the donation procedure may begin. The end of the WIT is denoted by the start of the cold preservation flush in the donor organ. DCD donor organs inevitably suffer hypoxia and hypoperfusion during progression to circulatory arrest and the "no-touch" period of warm, pulseless ischemia. Despite this, and because lungs may be able to better tolerate warm ischemia owing to low metabolic needs and localized storage of oxygen trapped in alveoli, evidence shows that lung allografts show acceptable outcomes after DCD procedures. The 2015 ISHLT DCD Registry Report compared DCD and matched DBD lung transplants and observed a comparable 5-year survival in both groups. ${ }^{19}$ 


\section{TARGETS FOR OPTIMIZATION OF HEART AND LUNG ALLOGRAFTS IN THE DONOR}

Management of both DBD and DCD donors to optimize cardiac and pulmonary function and to limit organ injury in the donor milieu requires hemodynamic, neuroendocrine, and organ-specific approaches. Table 4 outlines the standard therapies available to optimize allograft function in the donor. ${ }^{20}$

In 2009, a multicenter randomized controlled trial comparing a lung protective ventilation (LPV) strategy with conventional ventilation strategies in DBD donors showed that an LPV strategy improved the preharvest $\mathrm{PaO}_{2} / \mathrm{Fio}_{2}$ ratio in comparison with conventional ventilation practices. ${ }^{21,22}$ The recommended ventilation strategy for donors (Table 5) $^{23}$ suggests that appropriate LPV plays an important role in attenuating lung injury and optimizing donor lungs.

\section{CAUSES OF INJURY DURING ALLOGRAFT PRESERVATION: STATIC COLD STORAGE}

Traditionally, heart and lung allografts are preserved after the initiation of hypothermic (and in the case of heart allografts, cardioplegic) arrest of cell function by static cold storage. This involves the rapid flushing and cooling of the organ with an adapted crystalloid-based fluid, which optimally confers the following protection of the organ:

- Minimizes hypothermia-induced cell injury

- Buffers intracellular acidosis

\begin{tabular}{|c|c|}
\hline \multicolumn{2}{|l|}{ Hemodynamics } \\
\hline Hypovolemic shock & $\begin{array}{l}\text { i. Crystalloid repletion to achieve euvolemia } \\
\text { ii. Consider albumin } 5 \% \text { for fluid resuscitation } \\
\text { iii. Avoid hydroxyethyl starch fluid resuscitation }\end{array}$ \\
\hline Vasodilatory shock & $\begin{array}{l}\text { i. Goal central venous pressure } 6-8 \mathrm{~mm} \mathrm{Hg} \\
\text { ii. Goal mean arterial pressure }>60 \mathrm{~mm} \mathrm{Hg} \\
\text { iii. Vasopressin } 0.01-0.04 \mathrm{IU} / \mathrm{min} \text { to maintain } \\
\text { hemodynamic goals } \\
\text { iv. Consider the administration of inotropes to support } \\
\text { LV systolic and diastolic function with excessive fluid } \\
\text { requirements }\end{array}$ \\
\hline Cardiac shock & $\begin{array}{l}\text { i. Consider placement of pulmonary artery catheter to } \\
\text { tailor therapy } \\
\text { ii. Inotropes to optimize central venous pressure, mean } \\
\text { arterial pressure, and mixed oxygen saturation }\end{array}$ \\
\hline \multicolumn{2}{|l|}{ Hormonal } \\
\hline Diabetes insipidus (BDB donor) & $\begin{array}{l}\text { i. Vasopressin } 0.01-0.04 \mathrm{IU} / \mathrm{min} \text {, consider higher doses } \\
\text { with caution } \\
\text { ii. Desmopressin if persistent ongoing diabetes insipidus } \\
\text { with sodium }>145-150 \mathrm{mmol} / \mathrm{L}\end{array}$ \\
\hline Adrenal insufficiency & Intravenous methylprednisolone $15 \mathrm{mg} / \mathrm{kg}$ \\
\hline Thyroid deficiency & $\begin{array}{l}\text { Consider intravenous T3 }(4 \mu \mathrm{g} \text { bolus then } 3 \mu \mathrm{g} / \mathrm{h}) \text { or T4 } \\
(20 \mu \mathrm{g} \text { bolus then } 10 \mu \mathrm{g} / \mathrm{h}) \text { in unstable donor despite } \\
\text { hemodynamic optimization }\end{array}$ \\
\hline Hyperglycemia & Consider standard ICU management protocol \\
\hline
\end{tabular}

Adapted from Courtwright A, Cantu E. Evaluation and management of the potential lung donor. Clin Chest Med 2017;38(4):755; with permission. 


\begin{tabular}{|l}
\hline $\begin{array}{l}\text { Table } \mathbf{5} \\
\text { The recommended lung-protective ventilation }\end{array}$ \\
\begin{tabular}{ll} 
Objective & Parameters \\
\hline Prevention of alveolar overdistention & $\begin{array}{c}\text { Tidal volume } 6-8 \mathrm{~mL} / \mathrm{kg} \mathrm{IBW} \text {, plateau pressure } \\
<30 \mathrm{~cm} \mathrm{H}_{2} \mathrm{O}\end{array}$ \\
\hline Maintain alveolar recruitment & Adequate PEEP 8-10 $\mathrm{cm} \mathrm{H} \mathrm{H}_{2} \mathrm{O}$ \\
\hline Prevention of oxygen toxicity & Lowest $\mathrm{FiO}_{2}(\leq 0.5)$ to keep $\mathrm{SpO}_{2} 92 \%-95 \%$ \\
\hline
\end{tabular}
\end{tabular}

Abbreviations: IBW, ideal body weight; PEEP, positive end-expiratory pressure; $\mathrm{SpO}_{2}$, oxygen saturation by pulse oximetry.

Adapted from Mascia L, Pasero D, Slutsky AS, et al. Effect of a lung protective strategy for organ donors on eligibility and availability of lungs for transplantation: a randomized controlled trial. JAMA 2010;304(23):2620-7.

- Prevents expansion of the extracellular space by optimizing oncotic pressure

- Prevents injury from oxygen free radicals

- Prevents reperfusion damage caused by depletion of ATP stores

Static cold storage limits the storage time to a maximum of 4 to 6 hours in heart allografts and approximately 6 to 10 hours in lung allografts. In an ISHLT registry report examining the relationship between outcome of HTx and ischemia time of the allograft, ${ }^{4}$ an allograft ischemia time of less than 4 hours was associated with considerably higher survival than an allograft ischemia time of $\geq 4$ hours. ${ }^{4,24}$ Heart allografts exposed to longer periods of cold ischemia have been shown to confer worse survival in the years post transplant when compared with hearts subjected to shorter cold storage times (Fig. 5).

Lung allografts can survive better for longer in cold storage owing to the presence of small stores of oxygen trapped in the alveoli when lungs are preserved in a

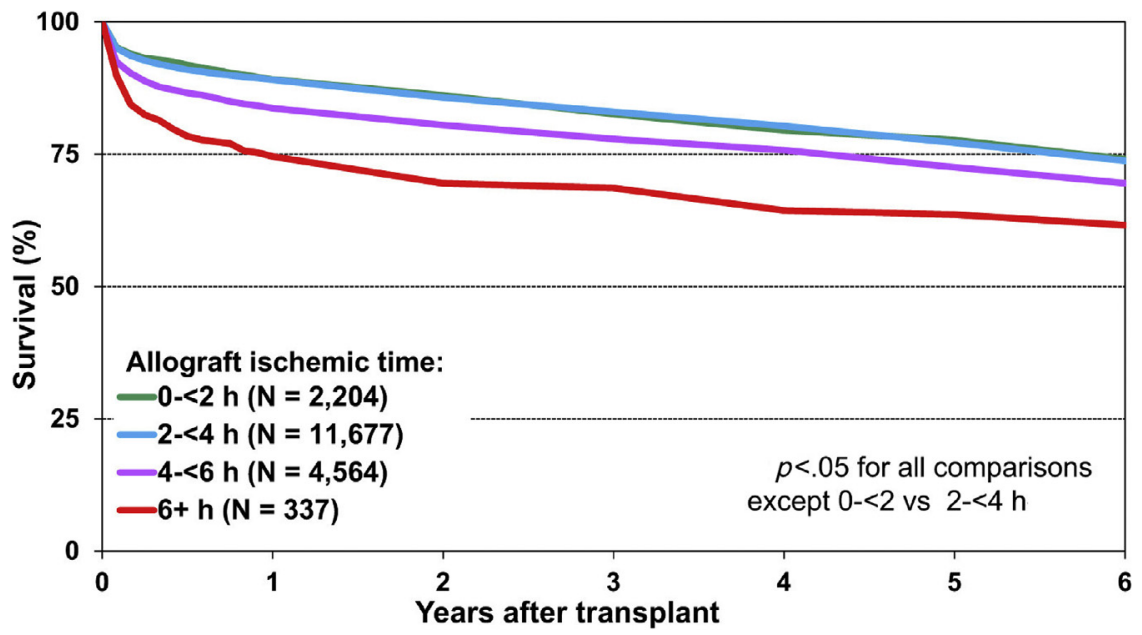

Fig. 5. Kaplan-Meier survival within 6 years by allograft ischemic time categories (adult heart transplants; January 2009 to June 2015). (From Lund LH, Khush KK, Cherikh WS, et al. The registry of the International Society for Heart and Lung Transplantation: Thirtyfourth Adult Heart Transplantation Report-2017; Focus Theme: Allograft ischemic time. J Heart Lung Transplant 2017;36(10):1044; with permission.) 
semi-inflated state. However, longer ischemia times are associated with poorer 30day survival post transplant ${ }^{1}$ (Fig. 6).

This time limit of effectiveness of cold storage geographically confines the donor pool available to a specific recipient, and is also a serious clinical problem if surgical preparation in the recipient is complex and reperfusion of the allograft is delayed. Examples of this are redo sternotomies in heart transplant recipients (eg, explantation of MCS) or pneumonectomy following pleurodesis in lung transplantation.

It is therefore necessary to develop ways of extending the time allografts can be safely preserved. However, other questions also drive the development of alternative methods of allograft preservation:

- Are there ways of functionally assessing allografts in an ex vivo setting?

- Are there techniques available to better preserve and treat allografts to attenuate injury and improve function following implantation?

\section{ALTERNATIVES TO COLD STORAGE ORGAN PRESERVATION Preservation of Heart Allografts}

The feasible alternatives to static cold storage confer differing potential advantages. First, continuous or repetitive cold perfusion of heart allografts during preservation allows one to extend the preservation time. In an experimental porcine model, donor hearts preserved for 24 hours were transplanted and showed acceptable function. ${ }^{25}$

The second alternative is to preserve heart allografts in a functioning, warm state. ${ }^{26}$ A platform for ex vivo heart perfusion (EVHP) has been developed and is in clinical use (Organ Care System [OCS]; Transmedics, Fig. 7). This facilitated a prospective, randomized, noninferiority trial (PROCEED II trial) ${ }^{27}$ comparing standard cold cardioplegic storage of human donor hearts with beating-heart allografts perfused and preserved ex vivo at normothermia with the OCS. In the standard group, the cold ischemia

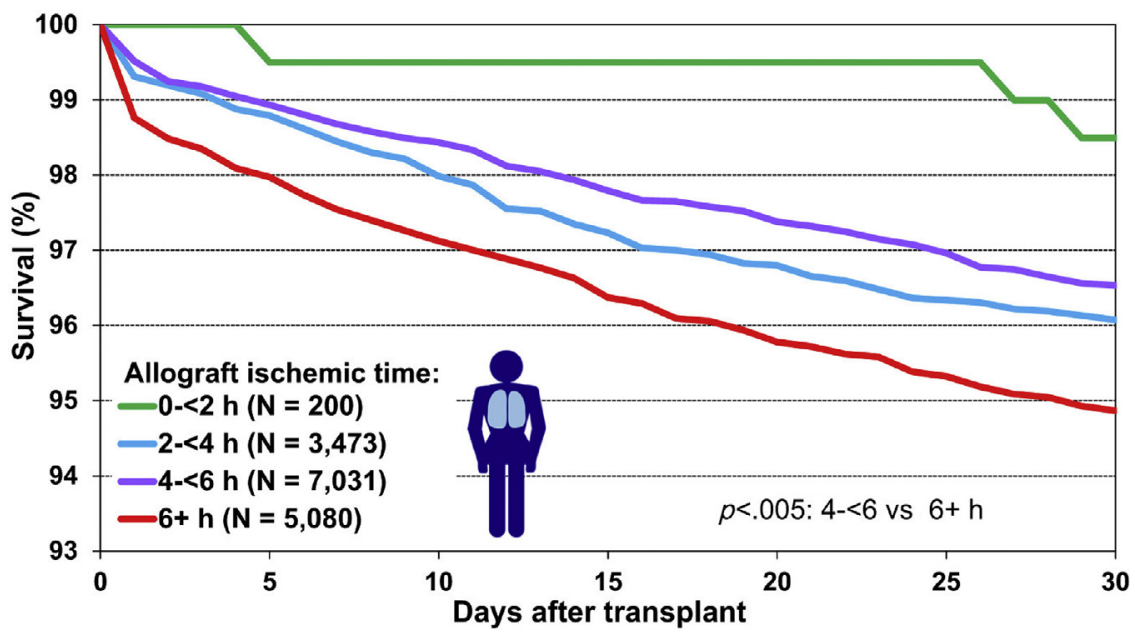

Fig. 6. Kaplan-Meier survival to 30 days for adult lung transplant recipients by allograft ischemic time (transplants: 2009 to June 2015). Log-rank test statistic with adjustments for multiple comparisons using the Scheffe method. (From Chambers DC, Yusen RD, Cherikh WS, et al. The registry of the International Society for Heart and Lung Transplantation: Thirty-fourth Adult Lung And Heart-Lung Transplantation Report-2017; Focus Theme: Allograft ischemic time. J Heart Lung Transplant 2017;36(10):1052; with permission.) 


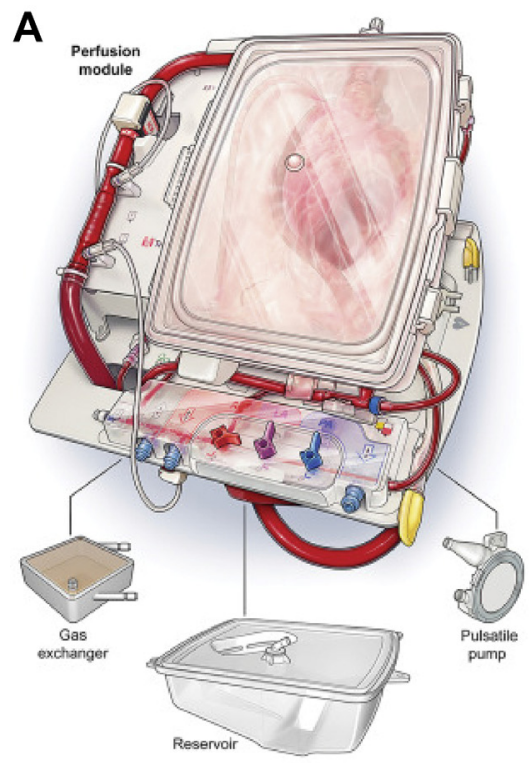

C

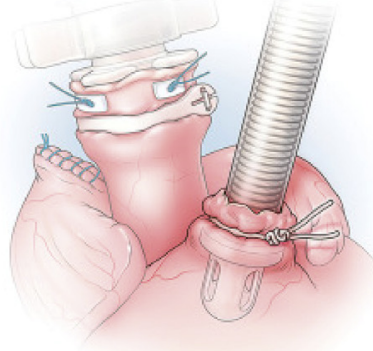

B

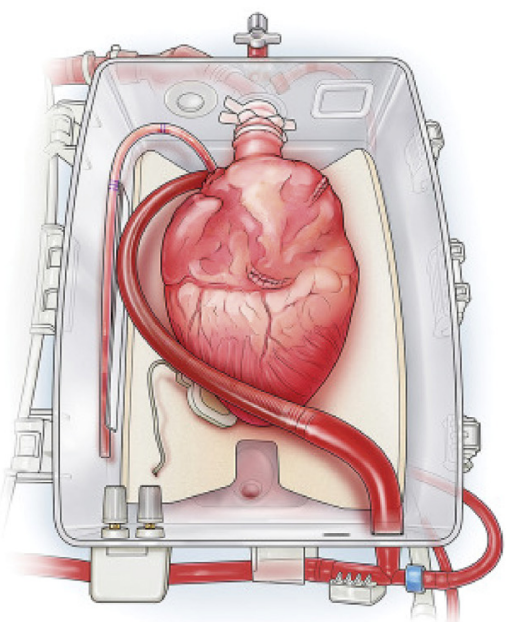

D

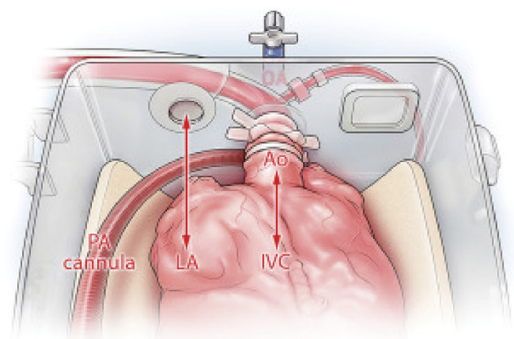

Fig. 7. Ex vivo heart perfusion (EVHP). EVHP is a platform providing the opportunity to perfuse, optimize, preserve in beating-heart state, and assess donor hearts. The only platform currently in clinical use is the Organ Care System, a portable system designed to be taken to the donor hospital and used directly after procurement of the donor heart. (A) Depiction of components. (B) Placement of donor heart within perfusion module. (C) Positioning of pulmonary artery cannula. (D) Ascending aortic cannula. (From Chan JL, Kobashigawa JA, Reich HJ, et al. Intermediate outcomes with ex-vivo allograft perfusion for heart transplantation. J Heart Lung Transplant 2017;36(3):259; with permission; and Courtesy of TransMedics, Andover, MA.)

time was 195 minutes and the 30 -day patient and graft survival rate was $97 \%(n=61)$. In the OCS group, the cold ischemia time was 113 minutes with a 30-day patient and graft survival of $94 \%(\mathrm{n}=63)(P=.45)$. Rates of cardiac-related adverse events, incidence of severe rejection, and length of ICU stay did not differ significantly between the groups.

The opportunity to limit the cold storage time and to biochemically functionally assess donor hearts on the OCS has emboldened the use of "extended criteria" 
heart allografts in HTx. A single-center experience described the use of EVHP in high-risk heart transplant procedures, ${ }^{28}$ defining high risk as either donor-related factors (estimated ischemic time $>4$ hours, left ventricular ejection fraction [LVEF] $<50 \%$, left ventricular hypertrophy, donor cardiac arrest, alcohol/drug abuse, and coronary artery disease) or recipient factors (MCS, elevated pulmonary vascular resistance, or both). Thirty hearts were preserved with the OCS, of which 26 were transplanted. Only one death was observed within the first year, with the remaining 25 patients demonstrating a well-preserved biventricular allograft function (LVEF of $66.3 \% \pm 5.6 \%$, mean longitudinal right ventricular systolic function of $13.6 \pm 3.1 \mathrm{~mm})$. This result demonstrates the role EVHP can play in optimizing outcome in "high-risk" heart transplant procedures, possibly by attenuating injury in "extended criteria" allografts, and allows investigators to explore the possibility of using heart allografts from DCD donors.

Traditionally, heart allografts from DCD donors have been considered unsuitable for transplantation because of the warm ischemia to which the allografts are exposed. The period between the withdrawal of life support and organ harvesting subjects the heart allografts to multiple injuries, including hypoxia, hypoperfusion, and ventricular distension. One study investigated the role of EVHP in DCD HTx in a porcine model looking at DCD hearts exposed to 30 minutes of warm ischemia, which were then preserved with either 4 hours of EVHP or 4 hours of standard cold storage. ${ }^{29}$ Five of 6 hearts in the EVHP group displayed favorable lactate profiles during EVHP and were successfully weaned off cardiopulmonary bypass. All hearts transplanted from the cold storage group demonstrated acute severe PGD and could not be weaned. This beneficial role of EVHP in DCD heart allografts is thought to be linked to the restoration of perfusion enabling the return of aerobic cell metabolism and replenishment of cellular nutrients. This prevents ongoing ischemic injury and the reperfusion injury that follows.

In a study in humans comparing the outcome after HTx from DCD and DBD donors, ${ }^{30}$ EVHP was used for normothermic preservation, transport, and biochemical assessment in all DCD hearts. DCD heart retrieval used one of two differing techniques: normothermic regional perfusion (NRP) or direct procurement and perfusion (DPP). NRP describes a technique whereby perfusion is restored to the arrested heart while still in situ (with exclusion of the cerebral circulation). This approach enables post-warm-ischemia functional assessment of the heart in the donor by pulmonary artery catheter measurements and transesophageal echocardiography. This technique, however, is limited in numerous countries by ethical objection to the restoration of circulation in a deceased donor. The alternative to NRP is DPP, whereby the heart is removed directly after flush with a cold cardioplegia solution and installed and reperfused on EVHP. In DPP, functional assessment of the DCD heart is not possible and, therefore, levels of biomarkers in the EVHP perfusate are used to reflect allograft viability. The study was a single-center observational matched cohort study to compare patients who received transplants of DCD donor hearts with matched recipients who received transplants of DBD donor hearts. Twenty-eight DCD heart transplants were performed with almost equal numbers of DCD hearts procured by either NRP or DPP. Survival at 90 days (DCD 92\%, DBD 96\%, $P=1.0$ ), hospital length of stay, allograft function, and 1-year survival (DCD 86\%, DBD 88\%, $P=.98$ ) were comparable between groups. The retrieval method (NRP vs DPP) was not associated with a difference in outcome. Early cardiac output was, however, better in the DCD group ( $2.5 \mathrm{vs} 2.0 \mathrm{~L} / \mathrm{min} / \mathrm{m}^{2}, P=.04$ ), possibly explained by the avoidance of myocardial injury caused by the catecholamine storm during brain death in DBD donors and/ or a possible effect of ischemic preconditioning after WLST in DCD donors. 


\section{Developments and Controversies in Ex Vivo Heart Perfusion}

At present, clinical assessment of the allograft during EVHP relies on sampling lactate levels from the aortic root and pulmonary artery cannulas, using lactate trends as a surrogate for myocardial viability. Other biomarkers of myocardial injury, such a troponin, are of limited use ${ }^{31}$ given their elevation caused by nonspecific stresses during donation procedures. Currently there are no modalities to functionally assess heart allografts on EVHP, primarily as it is not possible to fully load and challenge a heart allograft on the OCS platform. Alternative platforms aiming to preserve heart allografts in a beating state while assessing function using pressure-volume loops generated under clinical loading conditions are being investigated.

Myocardial edema has been identified as an issue associated with prolonged preservation of heart allografts on EVHP, although it is uncertain whether the weight gain of the allograft translates to adverse outcomes. ${ }^{31}$ To attenuate myocardial edema, alternatives to the current perfusion solution and technique are being explored, aiming to optimize the oncotic pressures of the perfusion fluid and attempting to improve diastolic coronary perfusion while limiting excessive aortic root pressures. ${ }^{32}$

\section{ALTERNATIVES TO COLD STORAGE ORGAN PRESERVATION Preservation of Lung Allografts}

Cold storage is an acceptable method of preserving donor lungs provided that minimal injury has been incurred in the donor and that the ischemia times are not excessively long. There are, however, techniques offering alternatives to static cold storage, which have come through several noninferiority trials ${ }^{33,34}$ and which play vital roles in the use of marginal lung allografts.

The techniques make use of ex vivo lung perfusion (EVLP) technology enabling the perfusion, rewarming, and ventilation of donor lungs in a controlled setting. The first EVLP technique (Lund protocol) was originally designed with the intent of shortterm evaluation of DCD lungs ex vivo ${ }^{35}$ :

- Lund protocol

- Open left atrium

- Perfusate with type-matched red blood cells

- Performed on a static protocol-specific integrated system (Vivoline, XVIVO).

In 2016 a single-center study compared the short-term and long-term outcomes of recipients transplanted with initially rejected-for-transplant lungs that were then subjected to EVLP using the Lund protocol $(n=27)$ with recipients of non-EVLP (standard) lungs $(n=145)$ during the same period. There was no significant difference between short-term and long-term outcomes between the 2 groups. ${ }^{36}$

To achieve stable ex vivo perfusion of lungs for periods of up to 12 hours, the Toronto group developed several lung-protective strategies as additions to the Lund proto$\mathrm{col},{ }^{37,38}$ including reducing the flow through the lungs from $100 \%$ of the predicted cardiac output to $40 \%$ with the aim of reducing the incidence of hydrostatic lung edema:

- Toronto protocol (Fig. 8)

- Acellular perfusate

- Closed left atrium

- Performed on a static system encompassing equipment consisting of either individual parts or integrated in one unit (XPS perfusion system, XVIVO)

Furthermore, they preserved the left atrium in a closed state, facilitating maintenance of a positive left atrial pressure of 3 to $5 \mathrm{~mm} \mathrm{Hg}$ during EVLP. This approach 


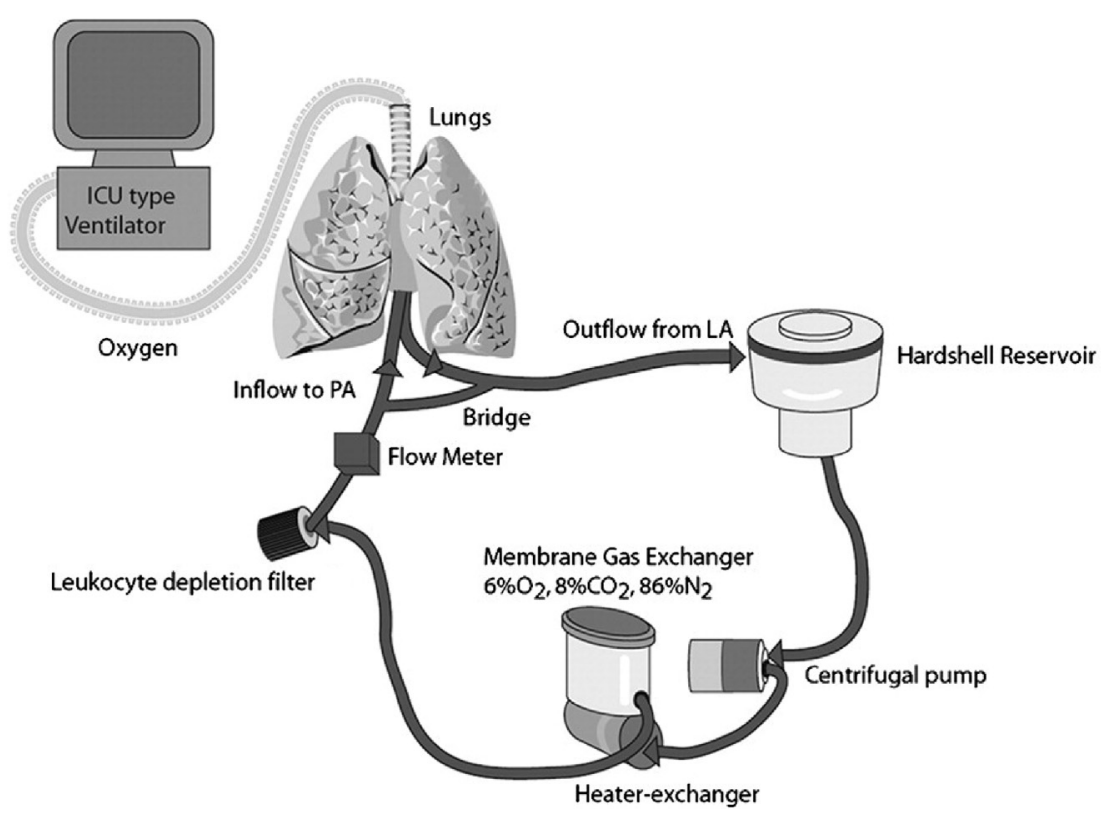

Fig. 8. Ex vivo lung perfusion (EVLP). Circuit for EVLP according to the Toronto protocol. EVLP is performed according to 3 protocols: the Toronto, Lund, and Organ Care System protocols. These protocols describe the perfusion and ventilation strategies of donor lungs (based on the predicted body weight of the donor). All protocols use a technique to deoxygenate the perfusate leaving the left atrium. The function of the donor lungs to oxygenate the perfusate is then possible by comparing the oxygen content of perfusate in the left atrium and pulmonary artery. Indications for EVLP: a poor to worsening $\mathrm{PaO}_{2} / \mathrm{FiO}_{2}$ ratio in the donor ( $<300$ with a positive end-expiratory pressure of $5 \mathrm{~cm} \mathrm{H}_{2} \mathrm{O}$ and an $\mathrm{FiO}_{2}$ of 1.0), a requirement to functionally assess the lungs, and logistics. Contraindications to EVLP: aspiration, bilateral infection, and diffuse traumatic contusion. The goals of the EVLP include functional assessment, improvement of lung function to a stable and sustainable situation, and protection from further injury. Lungs are assessed and accepted according to major criteria, which reflect the ability of the lungs to perform adequate gas exchange and also include assessment of the pulmonary vascular resistance and compliance of the lungs. A plain radiograph may aid in determining the etiology of lung injury. (Adapted from Cypel $M$, Yeung JC, Hirayama S, et al. Technique for prolonged normothermic ex vivo lung perfusion. J Heart Lung Transplant 2008;27(12):1320; with permission.)

was designed to tent open postcapillary venules in the lung and thus prevent their cyclical collapse, which occurs during ventilation. This adaptation was based on studies showing that absence of positive left atrial pressure can lead to unstable alveolar geometry ${ }^{39}$ and a reduction in lung compliance. ${ }^{40}$ The group published their first major study in $2011,{ }^{41}$ demonstrating that the incidence of PGD in high-risk donor lungs subjected to 4 hours of EVLP was comparable with that of conventional lung allografts (EVLP group $n=20$ vs conventional lung group $n=116$, incidence PGD III $15 \%$ vs $30 \%$ in the control group, $P=.11$ ). On the background of these positive clin-

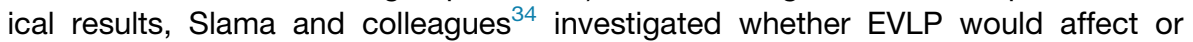
improve outcome when used for "standard" lung allografts. In a single-center trial, 41 standard lungs in a conventional (non-EVLP) group were compared with 39 standard lungs subjected to 4 hours of EVLP before transplantation. Although shortterm clinical outcomes did not differ between the groups, the incidence of PGD 
(grade $>1$ ) was lower in the EVLP group at all time points compared with the control group (24 hours: $5.7 \%$ vs $19.5 \%, P=.10$ ).

An alternative EVLP technique puts emphasis on reducing the cold ischemia time of lung allografts. A mobile EVLP unit (OCS system, Transmedics) has been developed to be taken to lung procurement procedures:

- OCS protocol

- Open left atrium

- Perfusate with type-matched red blood cells

- Portable equipment designed to be taken to the donor hospital and run during the transport of donor lungs

After cold flush, donor lungs are installed on the EVLP unit, perfused, rewarmed, and ventilated. The lungs are then kept on the EVLP for normothermic perfusion during transport and preservation for up to 5 hours until the lungs are cooled for a short period of cold ischemia to facilitate the surgical implantation procedure. Similar to the study using the Toronto protocol, a multicenter noninferiority, randomized trial ${ }^{33}$ (INSPIRE) comparing outcomes of transplant following preservation of standard lungs with either portable EVLP with the OCS $(n=141)$ or static cold storage $(n=165)$ demonstrated no clear short-term survival benefit from preservation with the OCS. However, there was a notable decrease in PGD in the EVLP arm of the study, with an incidence of PGD grade 3 within 72 hours post transplant of $17.7 \%$ in the OCS group and $29.7 \%$ in the static cold storage group $(P=.015)$.

\section{Developments and Controversies in Ex Vivo Lung Perfusion}

A platform providing access to perfusate, substrate obtained by bronchoalveolar lavage, and lung tissue in the context of normothermic, functional preservation of donor lungs is a hugely welcome research tool in understanding the etiology and pathophysiology of donor lung injury.

Further research strategies of interest include the role of (ultra-)protective ventilation strategies of lungs during EVLP to attenuate lung injury and eventual lung-induced biotrauma. Targeted protective ventilation strategies adapted to the individual lung, including concepts of open lung ventilation and prone ventilation, ${ }^{42}$ may lead to increased future use of marginal donor lungs (Video 1).

Still to be performed is a direct comparison of the EVLP protocols and platforms, and whether indeed certain platforms confer a clinically relevant optimization of allograft function in the context of specific injuries.

\section{PERIOPERATIVE MANAGEMENT OF LUNG ALLOGRAFTS}

Studies have shown that gradual reintroduction of blood flow during the reperfusion phase, over a 10-minute period, can significantly improve graft function. ${ }^{43}$ This prevents reperfusion of cold, atelectatic lungs with full normothermic cardiac output, which can lead to epithelial shear stress injury, ${ }^{44}$ inflammation, and lung edema.

In accordance with the principles of protective lung ventilation, the ventilation strategy after reperfusion of the lung allograft should maximize the tidal volume to 4 to $6 \mathrm{~mL} / \mathrm{kg}$ predicted body weight of the donor. This also includes keeping the $\mathrm{FiO}_{2}$ low during the early reperfusion period (ie, 0.21-0.5). ${ }^{11}$

Novel therapies for the optimization of donor lung function and attenuation of PGD are listed in Table 6. One of the most encouraging therapies is the prophylactic use of surfactant in donor lungs. A pilot study in $2017^{45}$ investigated the presence of surfactant proteins in lung allografts and concurrent rate of PGD in the recipient. The results 


\begin{tabular}{|c|c|c|c|c|}
\hline Therapy & Rationale & Design & Results & References \\
\hline $\begin{array}{l}N \text {-acetylcysteine } \\
\text { (intravenous) }\end{array}$ & $\begin{array}{l}\text { Limit generation of reactive } \\
\text { oxygen species (ROS) }\end{array}$ & $\begin{array}{l}\text { Porcine model of lung } \\
\text { transplant }\end{array}$ & $\begin{array}{l}\text { NAC-treated animals } \\
\text { developed less pulmonary } \\
\text { edema as measured by } \\
\text { EVLW index and less } \\
\text { protein and inflammatory } \\
\text { cytokines in BAL. NAC } \\
\text { therapy to both donor and } \\
\text { recipient improved } \\
\text { oxygenation, airway } \\
\text { pressure, and lung } \\
\text { compliance }\end{array}$ & Inci et al, ${ }^{48} 2010$ \\
\hline $\begin{array}{l}\text { Adenosine A2A receptor } \\
\text { agonist (intravenous) }\end{array}$ & $\begin{array}{l}\text { Limit ROS-dependent } \\
\text { cytokine production by } \\
\text { natural killer T cells via } \\
\text { modulation of NAPDH } \\
\text { oxidase } 2(\operatorname{NOX} 2)^{54}\end{array}$ & $\begin{array}{l}\text { Murine hilar clamping model } \\
\text { of EVLP and murine EVLP }\end{array}$ & $\begin{array}{l}\text { limits IRI-mediated lung } \\
\text { injury, less neutrophil } \\
\text { inflammation, cytokine } \\
\text { production, and } \\
\text { pulmonary edema } \\
\text { formation }\end{array}$ & Sharma et al, ${ }^{49} 2016$ \\
\hline $\begin{array}{l}\text { Diannexin (recombinant } \\
\text { homodimer of annexin } \mathrm{V} \text { ) } \\
\text { via pulmonary flush and } \\
\text { intravenous to the } \\
\text { recipient at time of } \\
\text { reperfusion } \\
\end{array}$ & Inhibition of apoptosis & $\begin{array}{l}\text { Rat model of lung } \\
\text { transplantation }\end{array}$ & $\begin{array}{l}\text { Reduced peak airway } \\
\text { pressure, limited EVLW, } \\
\text { attenuated } \\
\text { proinflammatory cytokine } \\
\text { production, suppressed } \\
\text { apoptosis }\end{array}$ & Hashimoto et al, ${ }^{50} 2016$ \\
\hline $\begin{array}{l}\alpha 1 \text {-antitrypsin (A1AT) } \\
\text { intravenous direct before } \\
\text { ischemia }\end{array}$ & Inhibition of apoptosis & $\begin{array}{l}\text { Rat IRI model, }{ }^{51} \text { pig model of } \\
\text { lung transplantation }{ }^{52}\end{array}$ & $\begin{array}{l}\text { Reduced pulmonary edema } \\
\text { formation, reduced lung } \\
\text { injury scores, improved } \\
\mathrm{PaO}_{2} / \mathrm{FiO}_{2} \text { ratios and lung } \\
\text { compliance }\end{array}$ & $\begin{array}{l}\text { Gao et al, }{ }^{51} 2014 \text {; Iskender } \\
\text { et al, }{ }^{52} 2016\end{array}$ \\
\hline
\end{tabular}




\begin{tabular}{|c|c|c|c|c|}
\hline \multicolumn{5}{|l|}{$\begin{array}{l}\text { Table } 6 \\
\text { (continued) }\end{array}$} \\
\hline Therapy & Rationale & Design & Results & References \\
\hline $\begin{array}{l}\text { Soluble RAGE ligand (sRAGE)/ } \\
\text { RAGE knockout }\end{array}$ & $\begin{array}{l}\text { Inhibiting receptor for } \\
\text { advanced glycation end } \\
\text { products (RAGE), a critical } \\
\text { mediator of acute lung } \\
\text { injury }\end{array}$ & $\begin{array}{l}\text { Mouse model of IRI using } \\
\text { hilar clamping }\end{array}$ & $\begin{array}{l}\text { Less pulmonary edema and } \\
\text { less histologic evidence of } \\
\text { lung injury }\end{array}$ & Sternberg et al, ${ }^{53} 2008$ \\
\hline $\begin{array}{l}\text { Aspirin and intrabronchial } \\
\text { DNase I treatment }\end{array}$ & $\begin{array}{l}\text { Reducing neutrophil } \\
\text { extracellular trap } \\
\text { formation, extracellular } \\
\text { deposits of chromatin } \\
\text { extruded by activated } \\
\text { neutrophils, which } \\
\text { sequester inflammatory } \\
\text { mediators }\end{array}$ & $\begin{array}{l}\text { Murine PGD model, BAL from } \\
\text { human lung transplant } \\
\text { recipients }\end{array}$ & $\begin{array}{l}\text { Limited lung injury within } 8 \mathrm{~h} \\
\text { of reperfusion, improved } \\
\text { lung permeability, } \\
\text { improved oxygenation }\end{array}$ & Sayah et al, ${ }^{54} 2015$ \\
\hline $\begin{array}{l}\text { Mesenchymal stem (stromal) } \\
\text { cells engineered to deliver } \\
\text { IL-10 }\end{array}$ & $\begin{array}{l}\text { Using the anti-inflammatory } \\
\text { and immunosuppressive } \\
\text { effects of IL-10 (inhibiting } \\
\text { cytokine synthesis, } \\
\text { downgrades the } \\
\text { expression of helper T cells) }\end{array}$ & Rat model of IRI & $\begin{array}{l}\text { Improved oxygenation, } \\
\text { reduced pulmonary } \\
\text { edema, reduced apoptosis, } \\
\text { and reduced T cell } \\
\text { infiltration after hilar } \\
\text { clamping }\end{array}$ & Manning et $\mathrm{al}^{55} 2010$ \\
\hline $\begin{array}{l}\text { Plasmin administration in the } \\
\text { EVLP perfusate }\end{array}$ & $\begin{array}{l}\text { Induces fibrinolysis, } \\
\text { destroying (micro)thrombi } \\
\text { in the donor lungs }\end{array}$ & Rat EVLP model & $\begin{array}{l}\text { Improved pulmonary } \\
\text { vascular resistance, } \\
\text { improved lung compliance, } \\
\text { and reduced pulmonary } \\
\text { edema formation }\end{array}$ & Motoyama et al, ${ }^{56} 2013$ \\
\hline Prone ventilation & $\begin{array}{l}\text { Protective lung ventilation } \\
\text { strategy aimed at reducing } \\
\text { or attenuating lung injury }\end{array}$ & Porcine EVLP model & $\begin{array}{l}\text { Improved } \mathrm{PaO}_{2} / \mathrm{Fio}_{2} \text { ratios, } \\
\text { reduced extravascular lung } \\
\text { water, lowered interleukin- } \\
1 \beta \text { levels }\end{array}$ & Niikawa et al, ${ }^{42} 2019$ \\
\hline
\end{tabular}


showed that low levels of surfactant protein gene expression in the lung donor before preservation and implantation was linked to the development of PGD grade 3. Other studies showed that donor lungs exposed to endogenous surfactant before retrieval had significantly higher pulmonary function 1 month after transplantation, but that the benefit disappeared by the end of the first post-transplant year. ${ }^{46}$ There remains, however, a lack of prospective, randomized studies regarding the use of surfactant in lung allografts and its role in the prevention or treatment of PGD.

\section{PERIOPERATIVE MANAGEMENT OF HEART ALLOGRAFTS}

If the factors linked to the development of PGD have been taken into account and, where possible, attenuated, the perioperative management of heart transplant recipients remains mainly supportive, ensuring adequate oxygen delivery to, and perfusion of, the heart allograft combined with optimizing and supporting other organ systems. In the case of the development of PGD, supportive treatment involves a combination of inotropes and pulmonary vasodilators. ${ }^{47}$ If there is no response to escalating medical treatment, early initiation of short-term MCS is warranted. ${ }^{3}$

\section{SUMMARY}

Injuries sustained by donor heart and lung allografts during the transplantation process are multiple and cumulative. Optimization of allograft function plays an essential role in the short-term and long-term outcome of the recipient in terms of not only mortality and morbidity but also quality of life. Therapeutic targets to prevent or attenuate injury are to be found in the donor, during the preservation process, intraoperatively during transplantation, and in the postoperative management of the recipient. The newest and most promising methods of optimizing donor heart and lung allografts are to be found in alternative preservation strategies, which enable concomitant functional assessment of donor organs and also provide a modality to initiate therapies to treat injured allografts or prevent injury during reperfusion in the recipient.

\section{SUPPLEMENTARY DATA}

Supplementary data related to this article can be found online at https://doi.org/10. 1016/j.anclin.2019.08.010.

\section{REFERENCES}

1. Chambers C, Yusen RD, Cherikh WS, et al. The registry of the ISHLT report2017. J Heart Lung Transplant 2017;36(10):1047-59.

2. Segovia J, Cosío MD, Barceló JM, et al. RADIAL: a novel primary graft failure risk score in heart transplantation. J Heart Lung Transplant 2011;30(6):644-51.

3. Kobshigawa J, Zuckerman A, Macdonald P, et al. Report from a consensus conference on PGD after cardiac transplantation. J Heart Lung Transplant 2014; 33(4):327-40.

4. Lund LH, Khush KK, Cherikh WS, et al. The registry of the ISHLT report-2017. J Heart Lung Transplant 2017;36(10):1037-46.

5. Cosío MD, Gomez Bueno M, Almenar L, et al. Primary graft failure after heart transplantation. J Heart Lung Transplant 2013;32(12):1187-95.

6. Christie JD, Carby M, Bag R, et al. Report of the ISHLT working group on primary lung graft dysfunction part II: definition. J Heart Lung Transplant 2005;24(10): 1454-9. 
7. Snell GI, Yusen RD, Weill D, et al. Report of the ISHLT working group on primary lung graft dysfunction, part I. J Heart Lung Transplant 2017;36(10):1097-103.

8. Diamond JM, Arcasoy S, Kennedy CC, et al. Report of the ISHLT working group on primary lung graft dysfunction, part II: epidemiology. J Heart Lung Transplant 2017;36(10):1104-13.

9. Whitson BA, Prekker ME, Herrington CS, et al. PGD and long-term pulmonary function after lung transplantation. J Heart Lung Transplant 2007;26:1004-11.

10. Liu Y, Lui $Y$, Su L, et al. Recipient-related clinical risk factors for $P G D$ after lung transplantation. PLoS One 2014;9(3):e92773.

11. Diamond JM, Lee JC, Kawut SM, et al, Lung Transplant Outcomes Group. Clinical risk factors for PGD after lung transplantation. Am J Respir Crit Care Med 2013; 187(5):527-34.

12. Shah RJ, Diamond JM, Cantu E, et al. Objective estimates improve risk stratification for PGD after lung transplantation. Am J Transplant 2015;15:2188-96.

13. Krutsinger D, Reed RM, Blevins $A$, et al. Lung transplantation from donation after cardiac death. J Heart Lung Transplant 2015;34(5):675-84.

14. Shigemura N, Bhama J, Gries CJ, et al. Lung transplantation in patients with prior cardiothoracic surgical procedures. Am J Transplant 2012;12:1249-55.

15. Steen S, Sjöberg T, Liao Q, et al. Pharmacological normalization of circulation after acute brain death. Acta Anaesthesiol Scand 2012;56:1006-12.

16. Bezovic G, Steen S, Sjöberg T, et al. Circulation stabilizing therapy and pulmonary high-resolution CT in a porcine brain death model. Acta Anaesthesiol Scand 2015;60:93-102.

17. Atkinson C, FLoerchinger B, Qiao F, et al. Donor brain death exacerbates complement-dependent ischemia/reperfusion injury in transplanted hearts. Circulation 2013;127:1290-9.

18. Kootstra G, Daemen JH, Oomen AP. Categories of non-heart-beating donors. Transplant Proc 1995;27(5):2893-4.

19. Cypel M, Levvey BJ, van Raemdonck D, et al. ISHLT DCD registry report. J Heart Lung Transplant 2015;74:1278-82.

20. Courtwright A, Cantu E. Evaluation and management of the potential lung donor. Clin Chest Med 2017;38:751-9.

21. Mascia L, Pasero D, Slutsky AS, et al. Effect of a lung protective strategy for organ donors on eligibility and availability of lungs for transplantation. JAMA 2010; 304(23):2620-7.

22. Bansal R, Esan A, Hess D, et al. Mechanical ventilatory support in potential lung donor patients. Chest 2014;146(1):220-7.

23. Belzer FO, Southard JH. Principles of solid organ preservation by cold storage. Transplantation 1988;45:673-6.

24. Budrikis A, Bolys R, Liao Q, et al. Function of adult pig hearts after 2 and 12 hours of cold cardioplegic preservation. Ann Thorac Surg 1998;66:73-8.

25. Steen S, Paskevicius A, Liao Q, et al. Safe orthotopic transplantation of hearts harvested 24 hours after brain death and preserved for 24 hours. Scand Cardiovasc J 2016;50(3):193-200.

26. Hassanein WH, Zellos L, Tyrrell TA, et al. Continuous perfusion of donor hearts in the beating state extends preservation time and improves recovery of function. J Thorac Cardiovasc Surg 1998;116:821-30.

27. Ardehali A, Esmailian F, Deng M, et al. Ex-vivo perfusion of donor hearts for human heart transplantation (PROCEED II). Lancet 2015;385:2577-84. 
28. Garcia Sáez D, Bartlomiej Z, Sabashnikov A, et al. Evaluation of the OCS in heart transplantation with an adverse donor/recipient profile. Ann Thorac Surg 2014;98: 2099-106.

29. Iyer A, Gao L, Doyle A, et al. Normothermic ex vivo perfusion provides superior organ preservation and enables viability assessment of hearts from DCD donors. Am J Transplant 2015;15:371-80.

30. Messer S, Page A, Axell R, et al. Outcome after heart transplantation from DCD donors. J Heart Lung Transplant 2017;36(12):1311-8.

31. Collins MJ, Moainie SL, Griffith BP, et al. Preserving and evaluating hearts with ex vivo machine perfusion. Eur J Cardiothorac Surg 2008;34:318-25.

32. Beuth J, Falter F, Pinto Ribeiro RV. New strategies to expand and optimize heart donor pool:ex vivo heart perfusion and donation after circulatory death: a review of current research and future trends. Anesth Analg 2019;128(3):406-13.

33. Warnecke G, Van Raemdonck D, Smith MA, et al. Normothermic ex-vivo preservation with portable OCS Lung device for bilateral lung transplantation (INSPIRE). Lancet Respir Med 2018;6:357-67.

34. Slama A, Schillab L, Barta M, et al. Standard donor lung procurement with normothermic EVLP. J Heart Lung Transplant 2017;36(7):744-53.

35. Steen $\mathrm{S}$, Liao Q, Wierup PN, et al. Transplantation of lungs from non-heart-beating donors after functional assessment ex vivo. Ann Thorac Surg 2003;76:244-52.

36. Wallinder A, Riise GC, Ricksten SE, et al. Transplantation after EVLP. J Heart Lung Transplant 2016;35:1303-10.

37. Cypel M, Yeung JC, Hirayama S, et al. Technique for prolonged normothermic EVLP. J Heart Lung Transplant 2008;27:1319-25.

38. Cypel M, Keshavjee S. Extracorporeal lung perfusion (EVLP). Curr Opin Organ Transplant 2016;21:329-35.

39. Petak F, Habre W, Hantos Z, et al. Effect of pulmonary vascular pressures and flow on airway and parenchymal mechanics in isolated rat lungs. J Appl Physiol (1985) 2002;92:169-78.

40. Broccard AF, Vannay C, Feihl F, et al. Impact of low pulmonary vascular pressure on ventilator-induced lung injury. Crit Care Med 2002;30:2183-90.

41. Cypel M, Teung J, Liu M, et al. Normothermic EVLP in clinical lung transplantation. N Engl J Med 2011;364:1431-40.

42. Niikawa H, Okamoto T, Ayyat KA, et al. The protective effect of prone position on ischemia-reperfusion injury and lung function in an ex vivo porcine lung model. J Heart Lung Transplant 2019;157:425-33.

43. Bhabra MS, Hopkinson DN, Shaw TE, et al. Critical importance of the first 10 minutes of lung graft reperfusion after hypothermic storage. Ann Thorac Surg 1996; 61:1631-5.

44. Pierre AF, DeCampos KN, Liu M, et al. Rapid reperfusion causes stress failure in ischemic rat lungs. J Thorac Cardiovasc Surg 1998;116:932-42.

45. Belhaj A, Boven C, Dewachter L, et al. Influence of donor lung surfactant-A and -B protein expression on the development of PGD after lung transplantation. Ann Transplant 2017;22:361-9.

46. Strüber M, Fischer S, Niedermeyer J, et al. Effects of exogenous surfactant instillation in clinical lung transplantation. J Thorac Cardiovasc Surg 2007;133: 1620-5.

47. Rabin J, Kaczorowski DJ. Perioperative management of the cardiac transplant recipient. Crit Care Clin 2019;35:45-60. 
48. Inci I, Eme B, Jungraithmayr W, et al. Prevention of PGD in lung transplantation by N-acetylcysteine after prolonged cold ischemia. J Heart Lung Transplant 2010; 29(11):1293-301.

49. Sharma AK, LaPar DJ, Stone ML, et al. NOX2 activation of natural killer T cells is blocked by the adenosine A2A receptor to inhibit lung ischemia-reperfusion injury. Am J Respir Crit Care Med 2016;193(9):988-99.

50. Hashimoto K, Kim H, Oishi H, et al. Annexin $\mathrm{V}$ homodimer protects against ischemia-induced acute lung injury in lung transplantation. J Thorac Cardiovasc Surg 2016;151(3):861-9.

51. Gao W, Zhao J, Kim H, et al. alpha1-antitrypsin inhibits ischemia reperfusioninduced lung injury by reducing inflammatory response and cell death. J Heart Lung Transplant 2014;33(3):309-15.

52. Iskender I, Sakamoto J, Nakajima D, et al. Human alpha1-antitrypsin improves early post-transplant lung function. J Heart Lung Transplant 2016;35(7):913-21.

53. Sternberg DI, Gowda R, Mehra D, et al. Blockade of receptor for advanced glycation end product attenuates pulmonary reperfusion injury in mice. J Thorac Cardiovasc Surg 2008;136(6):1576-85.

54. Sayah DM, Mallavia B, Liu F, et al. Neutrophil extracellular traps are pathogenic in PGD after lung transplantation. Am J Respir Crit Care Med 2015;191(4):455-63.

55. Manning E, Pham S, Li S, et al. Interleukin-10 delivery via mesenchymal stem cells. Hum Gene Ther 2010;21(6):713-27.

56. Motoyama $\mathrm{H}$, Chen F, Oshumi A, et al. Protective effect of plasmin in marginal donor lungs in an EVLP model. J Heart Lung Transplant 2013;32(5):505-10. 